\title{
RISIKO PAJANAN BAHAN PENCEMAR TERHADAP PEKERJA PENGECATAN MOBIL DI PT.STEELINDO MOTOR KOTA PADANG
}

\author{
Erdi Nur ${ }^{1)}$, Burhan Muslim ${ }^{1)}$, Erick Zicof ${ }^{1)}$ \\ (') Poltekkes Kemenkes Padang)
}

\begin{abstract}
Car painting work is one of the jobs that are at great risk of impaired lung function. Paint particles consist of hazardous chemicals such as cadmium, chromium, plumbum, mercury, acrylic resin, isocyanate, and toluene solvents. These materials when proven to enter the respiratory tract can cause lung function disorders. The purpose of this study is to identify hazards, analyze dose-response, analyze exposure and analyze the risk characterization of pollutants. This research is descriptive by analyzing environmental health risks to pollutants around the work environment. The population is all sanding, picking, and painting workers totaling 21 people which become sample. The instruments used in this study were low volume air sampler (LVAS), thermo hygrometers, anemometers, scales, and checklists for observing activity patterns. Data analysis uses stages in environmental risk analysis. Respondents smoke at work as much as $47.6 \%$, and do not use APD $71.4 \%$. Pollutants that exceed the quality standard are dust $(0.1538 \mu \mathrm{g} / \mathrm{m} 3)$, and $\mathrm{Cd}(0.0025 \mu \mathrm{g} / \mathrm{m} 3)$. RQ value (life time) > 1 for all exposure materials, which means that agent risk is not safe after 30 years of work. Management needs to manage risks such as reducing concentration, exposure time, and frequency of exposure to safe limits by managing risk through a technological approach, socioeconomic approach, and an institutional approach.
\end{abstract}

Keywords: Risk Analysis; Workers; Car Paint Workshop

\begin{abstract}
Abstrak
Pekerjaan pengecat mobil merupakan salah satu pekerjaan yang berisiko besar terjadinya gangguan fungsi paru. Partikel cat terdiri dari bahan kimia berbahaya seperti cadmium, chromium, plumbum, merkuri, acrylic resin, isocyanate dan pelarut toluene. Bahan-bahan tersebut bila masuk dalam saluran pernafasan terbukti dapat menimbulkan gangguan fungsi paru. Tujuan penelitian ini untuk mengidentifikasi bahaya, menganalisis dosis-respon, menganalisis pemajanan dan menganalisis karakterisasi risiko bahan pencemar. Disain penelitian ini deskriftif dengan melakukan analisis risiko kesehatan lingkungan terhadap bahan pencemar yang ada di sekitar lingkungan kerja. Populasi adalah semua pekerja pengamplasan, pendempulan dan pengecatan berjumlah 21 orang yang langsung menjadi subjek penelitian. Instrumen yang dipergunakan dalam penelitian ini adalah low volume air sampler (LVAS), thermo hygrometer, anemometer, timbangan dan ceklist untuk melakukan observasi terhadap pola aktivitas. Analisis data menggunakan tahapan analisis risiko lingkungan. Subjek penelitian yang merokok saat bekerja sebanyak 47,6\%, dan tidak menggunakan APD $71,4 \%$. Bahan pencemar yang melebihi baku mutu adalah debu $(0,1538$ $\mu \mathrm{g} / \mathrm{m} 3)$, dan $\mathrm{Cd}(0,0025 \mu \mathrm{g} / \mathrm{m} 3)$. Nilai $R Q$ (life time) $>1$ semua bahan pajanan yang berarti pajanan agent risk tidak aman setelah karyawan bekerja selama 30 tahun. Pihak manajemen perlu melakukan pengelolaan risiko seperti menurunkan konsentrasi, waktu pajanan, dan frekuensi pajanan hingga ke batas aman dengan melakukan pengelolaan risiko melalui pendekatan teknologi, pendekatan sosial ekonomi, dan pendekatan institusional.
\end{abstract}

Kata Kunci : Analisis Risiko; Pekerja; Bengkel Cat Mobil 


\section{PENDAHULUAN}

Pekerja pengecatan mobil adalah salah satu bidang pekerjaan yang perlu mendapat perhatian karena jumlahnya yang terus berkembang, sementara itu risiko penyakit akibat kerjanya cukup besar. Salah satu penyakit akibat kerja pada pekerja pengecatan mobil tersebut adalah gangguan fungsi paru. Beberapa bukti dari hasil penelitian oleh American Lung Association yang dikutip oleh Bruce menyimpulkan bahwa kontaminasi udara oleh partikel-partikel pada lingkungan kerja merupakan faktor risiko bagi kesehatan pernafasan pekerja, dan penurunan pajanan dapat menurunkan risiko tersebut ${ }^{1}$. Penelitian yang dilakukan oleh Mirabelli et al (2012) menunjukkan bahwa pekerjaan yang prevalensi kejadian penyakit saluran pernafasannya paling tinggi adalah pekerja pengecatan mobil ${ }^{2}$. Sejalan dengan penelitian Rahhal et al (2017) pada bengkel pengecatan mobil di Palestina, menunjukkan prevalensi yang cukup tinggi yaitu sebesar $82 \%$ pekerja mengalami gangguan fungsi paru ${ }^{3}$.

Pekerjaan sebagai pengecat mobil merupakan salah satu jenis pekerjaan yang berisiko besar untuk terjadinya gangguan fungsi paru. Partikel cat dalam aktivitas pengecatan terdiri dari bahan kimia berbahaya seperti cadmium, chromium, plumbum, merkuri, acrylic resin, isocyanate dan pelarut toluene. Bahan-bahan tersebut bila masuk dalam saluran pernafasan terbukti dapat menimbulkan gangguan fungsi paru ${ }^{4}$. Gangguan fungsi paru pada pekerja pengecatan mobil dipengaruhi oleh banyak faktor, yang dapat dikelompokkan dalam dua kelompok yaitu penyebab langsung dan tidak langsung. Penyebab langsung yaitu partikel yang terinhalasi ke saluran nafas, sedangkan penyebab tidak langsung di antaranya adalah dari faktor pekerja atau karakteristik pekerja ${ }^{5}$.

Kumpulan bahan kimia yang terdapat dalam bahan cat tersebut dengan cara disemprotkan dengan alat spray painting dirubah menjadi bentuk aerosol, yaitu kumpulan partikel halus berupa cair atau padat. Bentuk tersebut akan sangat mudah terhisap oleh pengecat terutama jika tidak mengenakan masker, sehingga merupakan faktor risiko yang penting terhadap penurunan fungsi paru ${ }^{6}$. Paparan bahan pencemar dalam bahan cat yang mengandung zat kimia sangat mudah menguap dan dapat dihirup serta diserap melalui kulit. Bahan pencemar tersebut mengandung senyawa aromatic dan logam berat yang berpotensi menyebabkan kerusakan dengan diperparah dengan suhu lingkungan yang tinggi ${ }^{7}$.

Menurut Permenkes 70 Tahun 2016, kadar partikel terhirup (respirabel) dari aktivitas industri seperti pengecatan mobil ini ditetapkan nilai ambang batasnya sebesar $3 \mathrm{mg} / \mathrm{m}^{3}$. Artinya apabila selama 8 jam bekerja tiap harinya atau 40 jam selama seminggu, pekerja terpajan oleh partikel lebih dari $3 \mathrm{mg} / \mathrm{m}^{3}$, maka pekerja akan mempunyai risiko untuk terjadinya gangguan fungsi paru ${ }^{8}$. Sumber pencemar di lingkungan kerja bengkel cat mobil yaitu debu yang dihasilkan dari proses pengamplasan. Proses pengamplasan bertujuan 
untuk meratakan lapisan dompol. Pekerja yang terus menerus terpajan oleh debu akan mudah beresiko mengalami gangguan pernafasan.

PT. Steelindo Motor merupakan salah satu bengkel pengecatan mobil yang terbesar di Kota Padang. Hasil dari survei pendahuluan yang peneliti lakukan pekerja yang tidak memakai alat pelindung diri saat bekerja, dan mengeluhkan rasa sesak, batuk dahak dan iritasi mata ketika melakukan pekerjaan mengecat ke bodi mobil. Informasi dari pihak managemen, penyakit yang sering diderita oleh pekerja sebagian besar adalah penyakit saluran pernafasan. Tujuan penelitian ini adalah menganalisis pajanan bahan pencemar terhadap pekerja pengecatan mobil di PT. Steelindo Motor Kota Padang. Hasil analisis risiko dari pajanan bahan pencemar diharapkan nanti bisa digunakan oleh manajemen bengkel sebagai dasar dalam pengelolaan faktor risiko yang berkemungkinan dapat menganggu kesehatan para pekerja.

\section{METODE PENELITIAN}

Disain Penelitian ini deskriptif dengan melakukan analisis pajanan bahan pencemar terhadap pekerja bengkel cat mobil. Penelitian dilaksanakan pada salah satu bengkel cat mobil terbesar di Kota Padang yaitu PT. Steelindo Motor dan waktu penelitian mulai Februari - November 2019. Populasi penelitian adalah semua pekerja bagian administrasi, pengamplasan, pendempulan dan pengecatan berjumlah 21 orang. Semuanya dijadikan sebagai subjek penelitian dan ditetapkan beberapa kriteria inklusi seperti telah bekerja $\geq 1$ tahun dan lama bekerja 8 jam per hari. Sedangkan kriteria eksklusi yang ditetapkan adalah pekerja tidak bisa diwawancarai, pekerja sedang cuti dan pekerja sakit. Dari 21 orang subjek penelitian, semuanya memenuhi kriteria inklusi yang telah ditetapkan. Pemantauan udara ambien secara SNI dilakukan dengan instrumen Low Volume Air Sampler. Kelembaban dan suhu udara diukur dengan termohygrometer, dan kecepatan angin diukur dengan anemometer. Pengukuran berat badan dilakukan menggunakan timbangan dan ceklist untuk melakukan observasi terhadap pola aktivitas (merokok dan penggunaan APD).

Variabel studi dalam penelitian ini berupa konsentrasi bahan pencemar, waktu pajanan, frekuensi pajanan, durasi pajanan, umur, dan berat badan. Defenisi Operasional Variabel yaitu Konsentrasi bahan pencemar adalah Kadar bahan pencemar udara di bengkel cat mobil. Waktu pajanan adalah Jumlah jam kerja per hari di lingkungan kerja dimana pekerja terpajan bahan pencemar. Frekuensi Pajanan menunjukkan waktu yang dihabiskan pekerja untuk bekerja di bengkel dalam rentang waktu 1 tahun dimana pekerja terpajan bahan pencemar melalui inhalasi. Durasi Pajanan menerangkan berapa lama pekerja bekerja di bengkel dan terpajan dengan bahan pencemar melalui jalur inhalasi. Umur merupakan Usia pekerja saat penelitian dilakukan. Berat badan merupakan jumlah 
masa tubuh pekerja. Analisis data menggunakan analisis risiko lingkungan yang meliputi identifikasi bahaya, analisis dosis respon, analisis pemajanan, dan karakteristik risiko.

\section{HASIL PENELITIAN}

1. Hasil analisis karakteristik dan kebiasaan responden

Tabel 1. Karakteristik Antropometri Responden

\begin{tabular}{cccc}
\hline Variabel & Minimum & Maksimum & Mean \\
& & & \\
\hline Umur & 22 & 60 & 37,81 \\
\hline Berat badan & 49 & 101 & 62,38 \\
\hline Waktu Pajanan (jam/hari) & 8 & 8 & 8 \\
\hline Frekuensi Pajanan (hari kerja/th) & 294 & 306 & 301,4 \\
\hline Lama/Durasi Pajanan (th) & 1 & 10 & 3,57 \\
\hline
\end{tabular}

Karakteristik antropometri sampel (lihat tabel 1) menjelaskan bahwa umur responden rata-rata 37,81 tahun, berat badan $(\mathrm{Wb})$ rata-rata $62,38 \mathrm{~kg}$. Waktu pajanan $\left(\mathrm{t}_{\mathrm{e}}\right)$ rata-rata 8 jam per hari. Frekuensi pajanan (fe) rata-rata dalam satu tahun 301,4 hari/tahun dan durasi pajanan $\left(D_{t}\right)$ adalah 3,57 tahun.

Tabel 2. Kebiasaan Responden Saat Bekerja

\begin{tabular}{ccc}
\hline Variabel & Frekuensi & Persentase \\
\hline Merokok & 10 & 47,6 \\
\hline Penggunaan APD & 15 & 71,4 \\
\hline
\end{tabular}

Untuk melihat kebiasaan responden saat bekerja responden yang merokok saat bekerja sebanyak 10 orang (47,6\%), responden tidak menggunakan APD saat bekerja 15 orang $(71,4 \%)$.

2. Hasil Pengukuran

Tabel 3.Hasil rata-rata Pengukuran Bahan Pencemar pada bengkel cat mobil

\begin{tabular}{cccc}
\hline Pajanan & Lantai 1 & Lantai 2 & Baku mutu \\
& & & \\
\hline $\mathrm{Cd}$ & $0,0017 \mu \mathrm{g} / \mathrm{m}^{3}$ & $0,0025 \mu \mathrm{g} / \mathrm{m}^{3}$ & $0,002 \mu \mathrm{g} / \mathrm{m}^{3}$ \\
\hline $\mathrm{Pb}$ & $0,0375 \mu \mathrm{g} / \mathrm{m}^{3}$ & $0,050 \mu \mathrm{g} / \mathrm{m}^{3}$ & $0,05 \mu \mathrm{g} / \mathrm{m}^{3}$ \\
\hline $\mathrm{Cr}$ & $0,0369 \mu \mathrm{g} / \mathrm{m}^{3}$ & $0,047 \mu \mathrm{g} / \mathrm{m}^{3}$ & $0,05 \mu \mathrm{g} / \mathrm{m}^{3}$ \\
\hline Debu & $0,1538 \mu \mathrm{g} / \mathrm{m}^{3}$ & $0,1474 \mu \mathrm{g} / \mathrm{m}^{3}$ & $0,15 \mu \mathrm{g} / \mathrm{m}^{3}$ \\
\hline
\end{tabular}

Untuk hasil pengukuran diketahui pada lantai 1 bahan pencemar yang melebihi baku mutu adalah debu $(0,15 \mu \mathrm{g} / \mathrm{m} 3)$, sementara lantai 2 bahan pencemar yang melebihi baku mutu adalah $\mathrm{Cd}(0,0025 \mu \mathrm{g} / \mathrm{m} 3)$. Namun demikian hasil pengukuran tersebut perlu ditindaklanjuti atau dianalisis dengan mencari besaran nilai tingkat risiko ( $R Q$ ) baik pada kondisi real time maupun life time. Karakteristik risiko kesehatan dinyatakan sebagai risk quotient $(R Q)$ atau tingkat risiko. Karakterisasi risiko (RQ) dihitung untuk menentukan 
apakah agen risiko pada konsentrasi tertentu berisiko menimbulkan gangguan kesehatan pada pekerja.

\section{PEMBAHASAN}

\section{Karakteristik Antopometri dan Pola Aktivitas}

Responden yang paling rendah berumur 22 tahun dan paling tinggi berumur 60 tahun. Secara alamiah umur berpengaruh terhadap status kesehatan seseorang dengan bertambahnya usia lanjut seseorang akan diikuti penurunan semua fungsi organ tubuh sehingga pada masa lanjut usia akan terjadi penurunan daya tahan tubuh atau dengan kata lain rentan terhadap penyakit. Secara fisiologis dengan bertambahnya umur maka kemampuan organ-organ tubuh akan mengalami penurunan secara alamiah tidak terkecuali gangguan fungsi paru dalam hal ini kapasitas vital paru. Kondisi seperti ini akan bertambah buruk dengan keadaan lingkungan yang berdebu dan faktor-faktor lain seperti kebiasaan merokok, tidak tersedianya masker juga penggunaan yang tidak disiplin, lama paparan serta riwayat penyakit yang berkaitan dengan saluran pernafasan. Rata-rata pada umur 30-40 tahun seseorang akan mengalami penurunan fungsi paru yang dengan semakin bertambah umur semakin bertambah pula gangguan yang terjadi ${ }^{9}$.

Berat badan responden berkisar antara $49 \mathrm{~kg}$ sampai $101 \mathrm{~kg}$. Berat badan berbanding terbalik dengan besarnya intake pajanan terhadap tubuh, semakin berat badan seseorang, maka semakin aman orang tersebut dari paparan polutan udara Hal ini disebabkan karena terdapat jaringan lemak yang cukup banyak dan dapat melarutkan zat toksik. Pada seseorang dengan nilai berat badan kecil, maka semakin besar risiko yang diterima akibat paparan polutan udara yang masuk melalui inhalasi, karena dapat langsung berinteraksi dengan sel tubuh beberapa risk agent yang masuk ke dalam tubuh seseorang. oleh sebab itu status gizi responden harus selalu dipertahankan berada dalam kondisi yang idea ${ }^{9}$.

Masa kerja juga merupakan variabel yang sangat penting diperhatikan dalam analisis risiko lingkungan. Menurut penelitian Dwilestari et al. (2012) pada industri pengecatan mobil informal di Karasak, Bandung menyatakan bahwa pekerja yang mengecat setiap hari memiliki nilai timbal dalam darah lebih tinggi dibandingkan dengan pekerja yang hanya mengecat 2 - 4 kali per minggu. Selain itu, diperoleh hasil bahwa semakin lama masa kerjanya maka semakin tinggi nilai timbal dalam darah pekerja ${ }^{10}$. Waktu pajanan $\left(\mathrm{t}_{\mathrm{e}}\right)$ adalah jumlah jam kerja per hari yang dialami oleh pekerja. Hasil penelitian menunjukkan jam kerja responden adalah 8 jam per hari. Standar jam kerja adalah 7 jam dalam sehari atau 6 hari dalam seminggu atau 8 jam kerja dalam sehari atau 5 hari dalam seminggu ${ }^{8}$.

Frekuensi pajanan menunjukkan waktu yang dihabiskan pekerja untuk bekerja di bengkel pengecatan mobil dalam rentang waktu 1 tahun yang terendah 294 hari/tahun dan tertinggi 306 hari/tahun. Durasi pajanan menerangkan berapa lama pekerja bekerja di 
bengkel pengecatan mobil, durasi pajanan terendah adalah 1 tahun dan yang tertinggi 10 tahun. Beberapa penelitian menunjukan adanya hubungan antara masa kerja dengan fungsi paru ${ }^{11}$. Durasi pajanan sangat berpengaruh terhadap nilai intake, semakin lama karyawan bekerja maka nilai intake akan semakin besar dan risiko untuk mendapatkan efek yang merugikan kesehatan pun semakin tinggi pula. Besarnya nilai intake berbanding lurus dengan nilai konsentrasi bahan kimia, laju asupan, frekuensi pajanan dan durasi pajanan, yang artinya semakin besar nilai tersebut maka akan semakin besar asupan seseorang. Sedangkan asupan berbanding terbalik dengan nilai berat badan dan periode waktu ratarata, yaitu semakin besar berat badan maka akan semakin kecil risiko kesehatan ${ }^{12}$.

Hasil penelitian menunjukkan bahwa perilaku responden selama bekerja didapatkan 47,6\% merokok, dan $71,4 \%$ tidak menggunakan masker. Perilaku responden tersebut menjadi faktor yang ikut berperan besar terhadap intake bahan pencemar masuk ke dalam tubuh. Hal ini disebabkan semakin banyak jalur pemajanan polutan masuk ke dalam tubuh selain melalui inhalasi juga dapat masuk melalui saluran pencernaan dan kulit. Penelitian yang dilakukan pada Polantas di kota Kendari menunjukkan ada korelasi pemakaian Alat Pelindung Diri dan kadar $\mathrm{Pb}$ dalam darah ${ }^{13}$. Kebiasaan merokok di tempat kerja menambah risiko peningkatan kadar $\mathrm{Pb}$ dalam darah. Penelitian ini sesuai dengan yang dilakukan oleh Mayang (2016) ada hubungan antara kebiasaan merokok dengan kadar $\mathrm{Pb}$ dalam darah pada pekerja pengecatan industri karoseri ${ }^{14}$.

\section{Analisis Risiko Bahan Pencemar}

Pada penelitian ini, polutan udara yang berasal dari kegiatan proses pengecatan mobil terpapar masuk ke dalam tubuh manusia melalui jalur inhalasi. Untuk melakukan analisis dosis respon, laju inhalasi yang digunakan dalam penelitian ini adalah 0,83 $\mathrm{m}^{3} / \mathrm{jam}$ berdasarkan nilai default exposure factor US EPA ${ }^{15}$.

a. Identifikasi Bahaya

Hasil pengukuran kadar $\mathrm{Cd}$, $\mathrm{Cr}$, dan debu pada lantai 1 bahan pencemar yang melebihi baku adalah debu $\left(0,1538 \mu \mathrm{g} / \mathrm{m}^{3}\right)$, sementara lantai 2 bahan pencemar yang melebihi baku adalah $\mathrm{Cd}=0,0025 \mu \mathrm{g} / \mathrm{m}^{3}$. Cd merupakan logam yang cukup berbahaya bagi tubuh kita. Cadmium dapat masuk ke dalam tubuh melalui sistem pernafasan akan terakumulasi di organ-organ tubuh tertentu, sehingga dapat menyebabkan terjadinya gangguan kesehatan, seperti kerusakan ginjal, liver, kerapuhan tulang atau gangguan lainnya. Sementara terpapar kromium (VI) melalui terutama inhalasi aerosol berakibat efek saluran pernafasan, karsinogenik, hati dan ginjal ${ }^{16}$. Keberadaan timbal $(\mathrm{Pb})$ di udara ambien diketahui dapat menyebabkan dampak buruk bagi kesehatan manusia, di antaranya mengganggu biosintensis hemoglobin dan menyebabkan anemia, kenaikan 
tekanan darah, kerusakan ginjal, gangguan sistem saraf, merusak otak dan menurunkan IQ serta konsentrasi dan menurunkan fertilitas pria melalui perusakan sperma ${ }^{13}$.

b. Analisis Dosis Respon

Dosis konsentrasi yang selanjutnya disebut $R f C$ adalah nilai yang dijadikan referensi untuk nilai yang aman pada efek non karsinogenik suatu agen risiko. PM10 di hitung dari baku mutu lingkungan $150 \mu \mathrm{g} / \mathrm{m}^{3}=0,15 \mathrm{mg} / \mathrm{m}^{3}$. Dari hasil analisis diperoleh nilai $R f C$ sebesar 0,0124 mg/kg/hari. Besaran nilai $R f C P b$ sebesar 0,000493 mg/kg/hari (disadur dari Direktorat Jendral PP dan PL,2012), Cromium (Cr VI) di hitung dari NAB $=0,05$ $\mu \mathrm{g} / \mathrm{m}^{3}$ berdasarkan Permenkes 70 Tahun 2016. Dari hasil analisis diperoleh nilai RfC sebesar 0,0041 mg/kg/hari Kadmium (Cd) di hitung dari $\mathrm{NAB}=0,002 \mu \mathrm{g} / \mathrm{m}^{3}$ menurut Permenkes 70 tahun 2016. Dari hasil analisis diperoleh nilai RfC sebesar 0,00016 $\mathrm{mg} / \mathrm{kg} / \mathrm{hari}$.

c. Analisis Pajanan

Analisis pajanan dilakukan dengan mengukur atau menghitung intake/asupan dari agen risiko. Hasil analisis menunjukkan intake real time masih di bawah baku mutu. Intake real time yang rendah belum menjamin aman bagi tenaga kerja karena harus dicari lebih lanjut karakterissasi risiko dari masing-masing agen risiko.

d. Karakterisasi Risiko

Karakterisasi risiko dilakukan untuk menetapkan tingkat risiko atau dengan kata lain menentukan apakah agen risiko pada konsentrasi tertentu yang dianalisis pada ARKL berisiko menimbulkan gangguan kesehatan pada masyarakat (dengan karakteristik seperti berat badan, laju inhalasi/ konsumsi, waktu, frekuensi, durasi pajanan yang tertentu) atau tidak. Besarnya nilai $R Q$ realtime untuk kedua lantai diperoleh $R Q<1$, artinya pekerja masih aman untuk saat ini dari pengaruh pajanan bahan pencemar, Walaupun nilai $R Q<1$ bukan berarti kondisi telah aman bagi pekerja, oleh sebab itu perlu dilakukan analisis dengan menghitung nilai $R Q 30$ tahun atau $R Q$ (life time). Dari hasil perhitungan semua agen risiko diperoleh nilai $R Q>1$ artinya pajanan agent risk tidak aman untuk frekuensi pajanan selama 250 hari/tahun setelah karyawan bekerja selama 30 tahun.

\section{Pengelolaan Risiko}

\section{a. Strategi Pengelolaan Risiko}

Hasil analisis dapat ditarik kesimpulan bahwa untuk melindungi pekerja pada lantai 1 terhadap dampak dari pajanan maka sebaiknya berpedoman pada tE, fE, dan Dt terkecil, yaitu tE 5,6 jam/hr, fE 175,7 hari/th, dan Dt 21,08 tahun. Sementara untuk melindungi pekerja pada lantai 2 terhadap dampak dari pajanan maka sebaiknya berpedoman pada tE 4,18 jam/hr, fE 130,5 hari/th, dan Dt 15,66 tahun. 
Strategi pengelolaan risiko meliputi penentuan batas aman yaitu dengan penurunan konsentrasi hingga ke batas aman ( $\mathrm{C}$ aman), pembatasan waktu pajanan hingga ke batas aman (tE aman), dan pembatasan frekuensi pajanan hingga ke batas aman ( $\mathrm{fE}$ aman). Perhitungan batas aman dilakukan terhadap responden yang paling berisiko ( $R Q$ paling besar) pada masing-masing lokasi pengukuran.

b. Cara Pengelolaan Risiko

Cara pengelolaan risiko dapat dilakukan dengan pendekatan teknologi, pendekatan sosial ekonomi, dan pendekatan institusional ${ }^{17}$.

1) Pendekatan Teknologi

Pengelolaan risiko menggunakan teknologi yang tersedia meliputi penggunaan alat, bahan, dan metode serta teknik tertentu. Upaya mengurangi bahan pajanan di ruang produksi dapat dilakukan dengan menggunakan bahan seeffisien mungkin.

Meletakkan ekshausfan di setiap sudut ruangan, sehingga lebih maksimal menghisap bahan pajanan dalam ruang produksi, dan jumlah atau ukuran ekshausfan sesuai dengan luas ruangan. Kebersihan terhadap ruang produksi perlu dilakukan setelah bekerja juga akan mengurangi keefektifan dalam mencegah paparan polutan udara. Ruangan perlu juga dilengkapi dengan kipas angin, guna mempercepat pengeluaran bahan pajanan di dalam ruang produksi. Meletakkan tanaman penyerap pulutan di dalam ruang produksi seperti Puring (Codiaeum Variegatum), Marginata (Dracaena marginata) dan Palem bamboo ${ }^{18}$.

Agar tanaman anti polutan ini dapat melakukan fungsinya dengan sempurna, saat perawatan perlu di lap permukaan daun secara berkala dengan kapas dan air, karena pori-pori pada daun tanaman merupakan bagian yang berfungsi menyerap zat-zat beracun. Dengan mengelap pori-pori daun terbebas dari selimut debu apalagi tanaman di dalam ruang tidak terkena air hujan yang dapat meluruhkan debu-debu yang menempel. Selain itu perlu mengeluarkan tanaman ke luar ruangan agar mendapatkan pasokan sinar matahari yang cukup. Setidaknya, setiap 2 atau 3 hari sekali, jemur tanaman tersebut di halaman.

2) Pendekatan sosial-ekonomis

Pendekatan sosial-ekonomis dapat dilakukan dengan pemberdayaan terhadap pekerja. Pencegahan pajanan membutuhkan peran aktif dari pekerja dalam penggunaan alat pelindung diri.

Pihak managemen perlu memberikan kompensasi pada pekerja dengan menyediakan susu dan wajib diminum setelah selesai produksi agar tubuh dapat dengan maksimal menetralisir racun yang ada dalam tubuh. Memberikan waktu istirahat di luar ruang produksi minimal 1 jam setiap proses produksi berlangsung, 
setiap pekerja perlu dilakukan pemeriksaan kesehatan secara berkala minimal 6 bulan sekali.

3) Pendekatan Institusional

Pengelolaan risiko dengan pendekatan institusional antara lain: kerjasama dalam pengelolaan limbah B3, kerja sama dalam mendukung pengawasan yang dilakukan oleh pemerintah, menyampaikan laporan kepada instansi yang berwenang. Pihak pemerintah dalam hal ini Balai Hyperkes maupun Dinas kesehatan perlu melakukan pengawasan dan pembinaan terhadap bengkel pengecatan mobil dalam rangka peningkatan kesehatan pekerja dan perlu mendapat dukungan dari pihak manajemen.

\section{SIMPULAN DAN SARAN}

Hasil penelitian tentang analisis risiko pajanan bahan pencemar terhadap pekerja pengecatan mobil dapat disimpulkan bahwa bahan pencemar yang melebihi baku mutu adalah debu $(0,1538 \mu \mathrm{g} / \mathrm{m} 3)$, dan $\mathrm{Cd}(0,0025 \mu \mathrm{g} / \mathrm{m} 3)$. Nilai $R Q$ (life time) $>1$ semua bahan pajanan yang berarti pajanan agent risk tidak aman setelah karyawan bekerja selama 30 tahun.

Pihak manajemen perlu melakukan pengelolaan risiko seperti menurunkan konsentrasi, waktu pajanan, dan frekuensi pajanan hingga ke batas aman dengan melakukan pengelolaan risiko melalui pendekatan teknologi, pendekatan sosial ekonomi, dan pendekatan institusional.

\section{DAFTAR PUSTAKA}

1. Ahmed A, El-ebiary AA, El-maddah El. Pulmonary Toxicity Among Car Spray Painters. Mansoura J Forensic Med Clin Toxicol. 2010;18(1):51-64.

2. Mirabelli MC, London SJ, Charles LE, Pompeii LA, Wagenknecht LE. Occupation and the prevalence of respiratory health symptoms and conditions: The atherosclerosis risk in communities study. J Occup Environ Med. 2012;54(2):157-65.

3. Rahhal B, Hamadallah Y, Taqatqah O, Shadeed I, Hattab S. The impact of automobile painting profession on selected respiratory parameters: A study from Palestine. J Mater Environ Sci. 2017;8(8):2877-83.

4. IARC monographs. Chemical agents and related occupations. IARC Monogr Eval Carcinog Risks Hum [Internet]. 2012;100(Pt F):9-562. Available from: http://www.ncbi.nlm.nih.gov/pubmed/23189753

5. Deviandhoko, Nur Endah W N. Faktor-Faktor Yang Berhubungan Dengan Gangguan Fungsi Paru Pada Pekerja Pengelasan di Kota Pontianak Factors Are Related With Pulmonary Function Disorders On Welding Workers In The Pontianak Cit y. 
2012;11(2):123-9.

6. Roberge B, Aubin S, Ostiguy C, Lesage J. Guide for Safe Use of Isocyanates-An Industrial Hygiene Approach. Montreal, Canada, RG-764, IRSST. 2013.

7. Castaño BP, Ramírez V, Cancelado JA. Controlling Painters' Exposure to Volatile Organic Solvents in the Automotive Sector of Southern Colombia. Saf Health Work [Internet]. 2019;10(3):355-61. Available from: https://doi.org/10.1016/j.shaw.2019.06.001

8. Permenkes 70 tahun 2016 tentang Kesehatan Lingkungan Industri. 2016.

9. Dyer C. The interaction of ageing and lung disease. Vol. 9, Chronic Respiratory Disease. 2012. p. 63-7.

10. Dwilestari H. dan Oginawati K. Analisis Hematologi Dampak Paparan Timbal Pada Pekerja Pengecatan (Studi Kasus: Industri Pengecatan Mobil Informal di Karasak, Bandung). Bandung; 2012.

11. Kim B, Yoon JH, Choi BS, Shin YC. Exposure assessment suggests exposure to lung cancer carcinogens in a painter working in an automobile bumper shop. Saf Health Work [Internet]. 2013;4(4):216-20. Available from: http://dx.doi.org/10.1016/j.shaw.2013.09.002

12. Green RE, Pain DJ. Risks to human health from ammunition-derived lead in Europe. Ambio [Internet]. 2019;48(9):954-68. Available from: https://doi.org/10.1007/s13280019-01194-x

13. Dewi Puspita $P$ Yusuf $S$ dan Dian Arum P. Faktor yang berhubungan dengan kadar Plubum dalam darah polisi lalu lintas di Kota Kendari. Vol. Voll.1 No., Jurnal Kesehatan Masyarakat. 2016.

14. Mayang Puspita Sari dkk. Hubungan Karakteristik Individu dan Pemakaian Alat Pelindung Diri (APD) dengan Kadar Timbal $(\mathrm{Pb})$ Dalam darah pada Pekerja Pengecatan di Industri Karoseri. 2016;Volume.IV.

15. United States Environmental Protection Agency. Update of Standard Default Exposure Factors. Risk Assess [Internet]. 2014;2004(July 2004):6. Available from: https://www.epa.gov/risk/update-standard-default-exposure-factors

16. Irianto K. Pencegahan dan Penanggulangan Keracunan Bahan Kimia Berbahaya. J Kesehat Masy. 2019; volume $7 \mathrm{~N}$.

17. Depkes. Pedoman Analisis Risiko Kesehatan Lingkungan. Jakarta: Dirjen PPM dan PL; 2012.

18. Keputusan Menteri Kesehatan Nomor HK 01.011menkes/153/2018. Petunjuk Teknis Gerakan Kantor Berbudaya Hijau dan Sehat (Berhias) Di Lingkungan Kementrian Kesehatan. 2018. 